Published in the Proceedings of the Aristotelian Society 100, 1999, pp. 34-51

\title{
A Distinction in Value: Intrinsic and For Its Own Sake
}

\author{
Wlodek Rabinowicz and Toni Rønnow-Rasmussen \\ Department of Philosophy, Lund University
}

Several philosophers have recently argued for a distinction between intrinsic and final value. Following G. E. Moore $(1903,1922,1993)$, an object is thought to be intrinsically valuable insofar as its value depends on ("supervenes on") its internal properties. It has final value if it is valuable 'as an end', 'for its own sake', rather than for the sake of something else. ${ }^{1}$ From a traditional point of view in moral philosophy, this seems to be a distinction without a difference: To value something for its own sake is to value it for the properties it has in itself, i.e., to value it intrinsically, on the basis of its internal properties.

This traditional view, however, has come under attack under recent years, notably by such philosophers as Christine Korsgaard (1983), Shelly Kagan (1992) and John O’Neill (1992). All of them argue for the following claim:

(C) There are final values that are not intrinsic.

Entailment in the other direction has nearly never been questioned, as far as we know: It seems to be a general if not a universal view that all intrinsic values are final. ${ }^{2}$ In this paper we do nothing to question this view. Instead, we focus on $(\mathrm{C})$ and try to give further support to this claim. ${ }^{3}$

Before we continue, it might be appropriate to clarify our usage of the notion of an internal property. The nowadays common identification of such properties with the non-relational features of the object should be

\footnotetext{
*This paper is dedicated to Peter Gärdenfors on the occasion of his $50^{\text {th }}$ birthday. The early drafts were presented in February 1999, at a Lund-Copenhagen symposium on intrinsic value, and then in March and May 1999, at the Departments of Philosophy in Stockholm and St Andrews. We are indebted to the participants of these meetings, and in particular to Lars Bergström, John Broome, Gunnar Björnsson, Krister Bykvist, Garrett Cullity, Åsa Carlson, Johan Brännmark, Klemens Kappel, Ulrik Kihlbom, Ian Law, Hans Mathlein, Derek Parfit, Ingmar Persson, Peter Sandoe, Caj Strandberg, Folke Tersman and, last but not least, Michael Zimmerman, for their interesting comments. We have also benefited from discussions with Bengt Brülde, Erik Carlson, Sven Danielsson, Dan Egonsson, Sten Lindström and Björn Petersson.

${ }^{1}$ A word of warning: 'Value as an end' is a somewhat misleading expression in the present context, as will be argued in the last section of this paper. The 'for its own sake'-idiom is more appropriate for what we have in mind. ${ }^{2}$ The only exception we know of is G. E. Moore, who in his Ethics suggests that for a thing to be "good for its own sake" it must be intrinsically good through and though: It cannot contain parts that are intrinsically bad or indifferent. Thus, for a (hedonistic) utilitarian, only pleasure is good for its own sake, while various wholes containing pleasure along with other components can at best be intrinsically good. They can be good for the sake of the pleasure they contain but not for their own sake. (Cf. Moore 1965 (1912), pp. 30-32.) In what follows, however, we ignore this special Moorean usage of "for its own sake".
} 
qualified: as we understand the term, the internal properties of an object are not just its non-relational properties but also the "internally relational" properties that it possesses in virtue of the relations it has to its own parts (components, elements, constituents, etc.). Thus, it is an internal property of a car that it has, say, four seats. And it is an internal property of a set that it has a car among its elements. ${ }^{4}$ For convenience, however, we shall in what follows use the expression "relational property" as a short for "externally relational property" (i.e., a property that an object has in virtue of its relation to something that is not one of its parts). Given this usage, relational properties will be contrasted with the internal ones.

We should also point out that, in our usage, an internal property of an object need not be essential to it. A concrete individual, such as, say, Theseus' ship, may well have internal properties that are contingent, say, such features as its colour or the property of containing as a part a particular plank, $a$. Abstract objects are a special case: their internal properties are necessary to them; they are essential to their identity. ${ }^{5}$ Note that the intrinsic value of a concrete individual object may well vary in different possible worlds, if this value supervenes on the object's contingent internal properties. Moore himself did not allow for this possibility. He insisted that "it is impossible for what is strictly one and the same thing to possess that value at one time, or in one set of circumstances, and not possess it at another" (Moore 1922, p. 260; cf. also Moore, 1903, p. 78, and 1993, p. 22). This seems to imply that the internal properties of a thing, on which its intrinsic value supervenes, must all be necessary to the thing in question. Here, however, we have decided to allow for contingent internal properties. This choice squares better with at least some of Moore's different remarks on the subject. In particular, it explains why Moore takes being exactly alike as equivalent to having the same intrinsic nature (i.,e., having the same internal properties; cf. the references given in fn 4 above). Surely, whether two objects are exactly alike might in part depend on their contingent features. ${ }^{6}$ According to our interpretation, then, intrinsic value may well supervene on the object's

\footnotetext{
${ }^{3}$ When this paper had already been completed, we came across a new paper by Kagan (1998). There are several striking similarities between his present views and ours, along with some important differences. See footnote 25 below, for a short summary of the similarities and the differences.

${ }^{4}$ Cf. Moore (1922, p. 261f, and 1993, p. 26f.) Moore would in addition require that the internal properties, both the non-relational and the internally relational ones, should all be purely qualitative in the broad sense of not being dependent on the numerical identity of objects. The "intrinsic nature" of an object, $a$, that comprises all of its internal properties, does not contain such properties as "being $a$ " or "having $b$ as a part". According to Moore, a part of what is meant by the claim that the intrinsic value of a thing depends solely on its intrinsic nature is that "anything exactly like it" must possess this value in the same degree (Moore, 1922, p. 261, cf. Zimmerman, 1988). The phrases 'having a different intrinsic nature' and 'not exactly alike' are "equivalent" for Moore (1922, p. 261). The same idea appears in Moore's posthumously published 'Preface to the second edition' of Principia Ethica, where he interprets intrinsic properties as properties that are invariant under the relation of being exactly alike (Moore, 1993, p. 23; cf, also ibid, p. 27). It seems to us that this requirement of "qualitativeness" should be avoided. That intrinsic value only depends on purely qualitative properties is certainly true; it is an implication of the universalizability principle. But it should not be made true just by the definition of an intrinsic value.

${ }^{5}$ For a short discussion of these issues, see Rabinowicz and Österberg (1996, p. 23). Cf. also Zimmerman (1998), who refers to Humberstone (1996) for an extended discussion of the different interpretations of the notion of an intrinsic (internal) property.

${ }^{6}$ Moore may have been misled by his choice of examples. When explicating the notion of an intrinsic nature, he tends to discuss purely perceptual objects, such as patches of colour or perceptual patterns. (Cf Moore 1922, p. 261ff
} 
contingent properties, as long as these properties are internal to the object and thus are independent of its external context. $^{7}$

\section{Non-intrinsic final values - first try}

In her argument for (C), Korsgaard assumes that an object is intrinsically valuable if the "source" of its goodness lies in the object itself. Then she suggests that for things valuable as ends, the source of their value may well be external - instead of being located in the objects themselves, it may lie in our interests or desires that are directed towards the objects in question (Korsgaard 1996a (1983), p. 252). ${ }^{8}$ Now, it seems to us that this argument for (C) is misdirected. The idea of a source of value is ambiguous between at least two interpretations: on the one hand, one may be thinking of the features of an object on which its final value supervenes (its "good-making" properties). If these features are internal to the object, i.e., non-relational, then the relevant value is intrinsic, as we are using this term. On the other hand, one may have in mind the constitutive grounds of an object's final value. The latter may well lie outside the object itself even though the former are internal to the object. To give an analogy: that a certain move in chess is admissible is a feature that supervenes on the internal properties of the move and of the situation on the chess-board. But the constitutive grounds of its being admissible are to be found in something external - in our conventions that determine the game of chess. Similarly, according to some preferentialist conceptions of value, preferences or desires may bestow a value on the object towards which they are directed. Still, if the object is being preferred for the features that are internal to it, then this externally constituted value is intrinsic: it supervenes on the internal properties of the object, precisely those properties for which the object is being preferred (cf. O'Neill 1992, Rabinowicz and Österberg 1996; for a critical discussion of this form of preferentialism, see Bykvist, 1998).

and 1993, p. 24.) For objects of this kind it is reasonable to assume that all their qualitative non-relational properties are essential to them. Needless to say, ordinary objects are different in that respect.

${ }^{7}$ This "context-independence" of intrinsic value has been questioned by ethical particularists. Thus, Jonathan Dancy distinguishes "between the features that form the resultance base for value [the set of properties 'in virtue' of which the object is valuable] (which in this case are intrinsic features of the value-bearer [...]) and other features whose presence or absence may affect the ability of the features in the resultance base to generate the value that they do." Since "[t]he latter features [...] may be features of other objects", intrinsic value may change even though intrinsic features remain constant. "Intrinsic value, then, though its resultance base may not be affected by changes in other objects, may yet itself be affected by such changes, where those changes affect the ability of the intrinsic resultance base to play [its] (perhaps normal) role." (Dancy, 1999) To put it differently, while Dancy takes intrinsic value to "result" from the internal properties of the object, he allows for the possibility that the class of properties on which intrinsic value supervenes includes both internal and relational properties. Resultance and supervenience are according to him different dependence relations (cf. Dancy, 1993, ch. 5, sections 1 and 2). In what follows, we disregard this interesting complication.

${ }^{8}$ Thus, Korsgaard writes: "Separating the two distinctions in goodness [intrinsic/extrinsic and final/instrumental], however, opens up another possibility: that of something which is extrinsically good yet valued as an end. An example of this would be something that was good as an end because of the interest that someone took in it, or the desire that someone had for it, for its own sake" (Op. cit. p. 252). As noted by Brülde (1998, p. 390), in her discussion of final value, Korsgaard does not clearly distinguish between being valued and being valuable (as an end, or for its own sake). In what follows, however, we focus on the latter. 
If our preferential attitudes are seen as the constitutive grounds of an object's final value, then it is natural to suppose that they confer value on the object not only in the actual world but also in other possible worlds towards which these attitudes may be directed. Consequently, they might confer value on objects even in those worlds in which our attitudes towards these objects would have been different from what they actually are. ${ }^{9}$ Thus, unlike the supervenience base, the constitutive grounds need not be present in all those possible worlds in which the object is supposed to be valuable (cf. Rabinowicz and Österberg, 1996, pp. 10 and 22f). ${ }^{10}$

Claims about the supervenience bases of value belong to axiology, while claims concerning the constitutive grounds are perhaps best seen as belonging to metaethics, even though the boundary between these two disciplines is not as clear-cut as one might wish. ${ }^{11}$ One might also try to express the distinction between supervenience and constitution in yet another way. We use to appeal to the properties on which the final value of the object supervenes as reasons for or against various actions taken for the sake of the object. But our preferences or desires that are directed towards the object cannot be appealed to as such reasons, at least not as long as it is a question of acting for the object's own sake. They must remain in the background rather than in the foreground of our motivational set. ${ }^{12}$ They can be the constitutive grounds of final value but this does not make them a part of its supervenience base.

It seems, then, that Korsgaard's claim that values as ends need not be "intrinsic" boils down to the assertion that the constitutive grounds of final values may well be external. This is still perfectly compatible with the view that all values as ends are intrinsic in our sense of the term, i.e., that they always supervene on the internal properties of their bearers. This apparent conflation of the supervenience base with the constitutive grounds still persists in Korsgaard (1998), where she reiterates the claim that our particular ends "have only extrinsic value, since their value depends on our own desires and interests in them and is conferred on them by our own rational choices" (1988, p. 63).

\footnotetext{
${ }^{9}$ In this respect, the analogy with chess is not perfect. A move that is permitted given our chess conventions would be forbidden if the conventions were different. While preferential attitudes as grounds for value are supposed to have an unlimited modal scope, chess conventions do not apply to all possible worlds.

${ }^{10}$ Michael Zimmerman (in personal communication) has objected to this "modal" way of characterizing the difference between the supervenience base and the constitutive grounds of value. As he points out, if our preferential attitudes in the actual world $w$ do confer value on an object a in various possible worlds - not just in $w$, but also in those possible worlds in which $a$ is not being preferred - then it still remains true that $a$ in all these worlds has a "world-indexed" property of being-preferred-in- $w$. Thus, if one admits the existence of such worldindexed properties, one might still insist that $a$ 's value in a possible world supervenes on its property of being preferred in the actual world. For the reasons given below, however, we do not find this view especially attractive.

${ }^{11}$ For a short discussion of this suggestion, due to Torbjörn Tännsjö, and for some possible objections to it, see Rabinowicz and Österberg (1996), pp. 25f.

${ }^{12}$ Cf. Pettit and Smith (1990) for a useful distinction between two potential roles of desire in decision making. Desires always belong to the motivating background of an agent's decision but only seldom figure in the foreground of his deliberation, as reasons that the agent would appeal to. It should be noted, however, that Korsgaard herself tends to assign a foregrounding role to our conative attitudes towards final values. In her discussion of "the instrumental principle", which requires us to take the means to our ends, she argues: "for the instrumental principle to provide you with a reason [to take the means], you must think that the fact that you will an end is $a$ reason for the end. [...] It means that your willing the end gives it a normative status for you ..." (Korsgaard, 1997,
} 
Brülde (1998, pp. 388f) also suggests that Korsgaard's idea of a source of value is ambiguous between two readings, but the ambiguity he identifies is different from the one we focus on. To say that an object has the source of its value in itself may mean, according to Brülde, either that the value supervenes on the object's intrinsic features or that its value is non-derivative, i.e., that it does not "inherit" its value from some other valuable object. It seems clear that this conflation is also present in Korsgaard's 1983 paper, along with the one pointed out above. According to Korsgaard's neo-Kantian view, the final value of our ends is derived from the intrinsic value of the good will, or "humanity" (= rational choice), that has these ends. "[G]oodness, as it were, flows into the world from the good will, and there would be none without it." (1996a (1983), p. 269) It should be noted that Korsgaard in her recent writings has given up her original conviction that what confers value (= the constitutive ground of final value) must ipso facto be valuable itself. She no longer believes that conferring value is some form of value transfer. Cf. Korsgaard (1996b) and (1996a, p. 407). As she puts this in her reply to Jerome Schneewind's criticisms: "More recently, especially in The Sources of Normativity, I have come to think of the value we place on ourselves as also conferred. To this extent, I agree with Schneewind that there is a continuity between the value of humanity and the value of other things: they are all the result of our own acts of conferring value. [...] I am aware that in early papers I made it sound too much as if value were some sort of metaphysical substance that gets transferred from us to our ends via the act of choice." (1998, p. 63f.) ${ }^{13}$ But, as previously mentioned, she still believes that the value of a thing must be extrinsic if it is conferred on it from the outside, by our rational attitudes and choices.

Non-intrinsic final values - second try

The conflation of the constitutive grounds of value with its supervenience base is also to be found in Kagan's paper. If intrinsic value is taken to be based solely on the object's internal properties, then, according to Kagan, value subjectivism would imply that intrinsic value does not exist. Nothing can be intrinsically valuable on "a radically subjectivist conception of value, according to which nothing would be valuable as an end in the absence of there being some creature who values it" (Kagan 1992, p. 184). Just as Korsgaard, Kagan here conflates the supervenience base of value with its constitutive ground: It is the latter, not the former, that according to the subjectivist conception is located in the creatures that value the object.

However, Kagan also provides another argument for (C) that is more relevant to our present concerns. The same argument is put forward by O'Neill. Both of them suggest that a thing may have value for its own sake in virtue of its relational features, such as uniqueness (Kagan 1992, p. 184) or rarity (O'Neill, 1992, p. 124). A rare or unique thing may be valued even when this thing is neither a means to something valuable nor a part of some larger

pp. 245-6). This view of Korsgaard, that willing an end can be one's reason for pursuing it, is convincingly criticised in Broome (1998).

${ }^{13}$ In what follows, the notion of "non-derivative" value will not be further discussed. Before we leave this issue, let us just mention that Brülde (ibid., pp. 7 and 392) takes non-derivative values to be a proper subset of final values. What is non-derivatively valuable is valuable for its own sake, but the opposite does not hold. For example, a whole 
valuable whole. "What is valued for its own sake might well be valuable in part because of various relational properties." (Kagan, ibid.) ${ }^{14}$ Note that, in this case, the final value of an object is supposed to supervene on a relational property: we value a thing on account of its being being rare or unique. Thus, it is no longer a question of conflating the constitutive grounds of value with its supervenience base. Whether such a valuation is plausible or not is a substantive issue that need not detain us here. ${ }^{15}$ But supposing it is plausible, what is the status of the value involved? This is the question we want to discuss. Thus, what we are interested in is a particular issue in formal theory of value.

If O’Neill and Kagan are right, it is easy to find many other cases of non-intrinsic final values. O’Neill gives an example from environmental ethics: a wilderness may be valuable in this way because of its being untouched by humans, which is clearly a relational property. Another class of examples involves cases in which a thing is valued for its own sake in virtue of its special relationship to a particular object, event, or person. An original, say, an original work of art, may be valued for its own sake precisely because it has the relational property of being an original rather than a copy. Its final value supervenes, in part, on its special causal relation to the artist. Princess Diana's dress may be another case in point. The dress is valuable just because it has belonged to Diana. This is what we value it for.

But, one might object, is it really a case of a non-instrumental value? Diana's dress is perhaps valuable merely as a means: merely because it allows us to establish an indirect connection to a person we admire or find important in one way or another. Having such a connection may be something that we set a final value on. Couldn't this be what is going on here? Not necessarily. Even if the desire to establish such an "affiliation" with Diana may well be a part of the causal explanation of our evaluative attitude towards the dress, this does not imply that the evaluative attitude itself is of the instrumental kind: if we idolise Diana, we do not simply find the dress useful for some purpose; we

may be valuable for its own sake and still it may be merely derivatively valuable, if its value derives from the value of its parts.

${ }^{14}$ For an early statement of a somewhat similar view, see Beardsley, 1965, pp. 1f. According to Beardsley, an object such as a rare stamp is valuable on account of its relational property (rarity), without for this reason being valuable for the sake of something else. Unlike Kagan and O'Neill, however, he does not want to draw the conclusion that an object of this kind is valuable for its own sake. Why he hesitates to make this step is unclear to us. It may well be the case that the distinction between value for its own sake and for the sake of something else may not be exhaustive. For all we know, there might be values that are neither. But why should the value of rare stamps belong to this special category? Beardsley's only argument seems to be that the stamp cannot be valued for its own sake because its value "can be taken away, without altering the stamp at all, simply by having the Post Office Department print a few hundred million more copies" (ibid., p. 1) But this simply pre-supposes that the valuation of an object for its own sake, if justified, must be based on the properties the object has in itself (the properties it would keep when its copies were made). However, it is precisely this presupposition that is being questioned by a proponent of claim (C).

${ }^{15}$ Michael Zimmerman is one of the sceptics. Why should an object such as a rare stamp be valuable for its own sake just on the account of its being rare? After all, the stamp also has other relational properties which make it valuable without, however, making it valuable for its own sake. For example, the property of facilitating communication. Why should rarity have such a special status then? (Cf. Zimmerman 1998). This is a fair worry, but we shall not dispel it here. Much the same kind of worry arises when someone asks why some of the intrinsic 
ascribe an independent value to it. Compare this with O'Neill's example: The wilderness is not simply instrumental in allowing us to come into contact with something (otherwise) untouched by humans. Even if we could never visit the wild area, it would still keep its value from our point of view.

But if Diana's dress is a good example of what we are after, then there are innumerable examples of a similar kind: Napoleon's hat, a gun that was used at Verdun, etc. In all these cases, a thing acquires a non-instrumental value in virtue of its causal relation to some person, object or event that stands out in some way. The final value of a thing comes from the importance of another thing. Note that there might be a connection between this kind of final value and the final value based on rarity. If many of Napoleon's hats are still around, the value of each of them may be considerably lower.

Korsgaard discusses a different type of cases in which the final value of a thing depends on its relational properties: We can say "of certain kinds of things, such as luxurious instruments, that they are valued for their own sakes under the condition of their usefulness [relational property]. Mink coats and handsome china and gorgeously enamelled frying pans are all things that human beings might choose partly for their own sakes under the condition of their instrumentality: that is, given the role such things play in our lives" (Korsgaard, 1996a (1983), p. 264). It is an interesting and somewhat paradoxical group of cases: the final value of a thing is here supposed to supervene, in part, on its instrumental value (or, alternatively, on the same relational property that makes the object instrumentally valuable). Being useful is, of course, not sufficient to make the mink coat valuable for its own sake; but it is a necessary pre-condition of the coat's final value.

\section{Reduction manoeuvre}

The ascription of value to an object on the basis of its relational properties can be met with the following response: When you say that an object, $\mathrm{X}$, is valuable for its own sake because of its relation to some other object or objects, what you really mean is that the value accrues to a state (or a fact) to the effect that the object $\mathrm{X}$ that has this relation exists. This valuable state contains the relevant relation as its component and so its value may be seen as intrinsic: the value of the state is based on the internal features of the state itself. For example, the value of the wilderness untouched by human hands is, according to this proposal, nothing but the intrinsic value of the state The wilderness untouched by human hands exists. Analogously, to say that Diana's dress is valuable for its own sake reduces to the claim that the state Diana's dress exists is intrinsically valuable. What was the external, relational property of the dress (its having belonged to Diana) is now seen as the internal feature of the state. Consequently, the value of the state is based on its internal properties and therefore is intrinsic (in the standard Moorean sense).

If this reduction is correct, there is no reason to assume the existence of final values that are not intrinsic. The statement that something has a final value on the basis of its relational properties is always reducible to the claim

features of the object make it valuable for its own sake, but others don't. Questions of this kind can only be answered by a substantive axiological theory and not by a formal theory of value. 
that some state that involves the object in question together with its relations to other objects is intrinsically valuable.

But is such a reduction reasonable? At first sight, it does not seem to be: it appears to put the cart before the horse. If the existence of the wilderness is valuable, it is because the wilderness itself is valuable. Thus, it is the state that derives its value from the object it involves and not the other way round. ${ }^{16}$ Consequently, the value of the object does not seem to be explicable in terms of the value of the state.

In fact, in some cases, one might even want to go further and question whether the existence of a valuable thing is always something to be valued. Does it follow that the existence of $\mathrm{X}$ is a valuable state, if $\mathrm{X}$ is a valuable object? As is well-known, this entailment was emphatically denied by Kant in connection with aesthetic value: the judgment that the object is aesthetically valuable does not in the least commit one to the conclusion that the object's existence is of value (Kant, 1913 (1790), § 2.) It may well be the same with some judgements to the effect that an object is valuable for its own sake. We take Diana's dress to be valuable, but do we think it is valuable that this dress exists? We might hold that, because of its value, the dress should be preserved or that it should not be destroyed, but do we think that the world is a better place because of the existence of that object? ${ }^{17}$

This shows, by the way, that the friends of the reduction might have a difficult time in identifying the precise state which is supposed to be valued. Is it the existence of the thing in question or is it rather its continued existence given that it already exists? Or perhaps it is not the continued existence of a thing that is good, but rather it ceasing to exist that would be bad? Or perhaps it would be bad only if the thing in question were wilfully destroyed? There are here several possibilities to choose between and it is not at all clear that there is just one right candidate. ${ }^{18}$

We may at this point, however, take a pause and ask a more fundamental question: why should anyone, in the first place, want to reduce the value of a thing to the value of a state? Several philosophers [Ross 1930, Harman 1967, von Wright 1963 and 1972, Chisholm 1968-69, Quinn 1974 and 1977, Oldfield 1977, Carlson 1995 and

\footnotetext{
${ }^{16}$ Anderson (1993, p. 26) goes as far as to suggest that, in general, "states of affairs which consist in the existence of something are valuable only if it makes sense to care about the thing that exists". To make the point we are making we need not subscribe to this general view.

${ }^{17} \mathrm{Cf}$. also Anderson (ibid.): "One may suppose that it doesn't make sense to care about anything unless it makes sense to care about its existence. [...] But the supposition is not true. It may make sense for me to love a person, but this does not imply that I must want that person to continue living. If he is gravely ill, it may be the best expression of my love for him to wish that he die quickly and mercifully."

${ }^{18}$ Another reduction possibility has been suggested to us by Ingmar Persson. That an object $\mathrm{X}$ is valuable in virtue of its property $\mathrm{P}$ amounts according to him to the claim that it is valuable that $X$ has $P$. At first sight, this seems like the old proposal in a new disguise: That $X$ has $P$ is logically equivalent to the state that $X$, which has $P$, exists. Still, as Persson points out, "the cart before the horse"-type of objection does not apply to his proposal: while the existence of $\mathrm{X}$, which has $\mathrm{P}$, may be valuable simply because $\mathrm{X}$, which has $\mathrm{P}$, is a valuable object, the same kind of response cannot be used with respect to the state that consists in $\mathrm{X}$ having $\mathrm{P}$. However, even if we accept this point and thus reject logical equivalence as the sufficient identity criterion for states, we might well wonder whether the proposed reduction is intuitively plausible. We take the dress to be valuable because it has belonged to Diana, but do we think it to be a valuable state of affairs that the dress has belonged to her? Why should one subscribe to such a strange value claim?
} 
1997, Feldman 1997, Bradley 1998, Brülde 1998, and Zimmerman 1998] argue for or simply assume that nothing but states (or facts) can be ultimately valuable. But what can be the motivation for such a radical position?

One reason (or at least one explanation) has to do with familiarity. The logic and the semantics of such modal propositional operators as "It is good that ...." or "that __ is better than that ...." has undergone an impressive development during the last forty years of this century. A value theorist who reduces all value to proposition-like objects can therefore fall back on a rather well-developed formal framework. Another reason has to do with simplicity. It is widely accepted that some states are intrinsically valuable. Consequently, a view that reduces all final value to the intrinsic value of states has the obvious advantages of monism. In particular, computing the values of the wholes on the basis of the values of their parts is greatly facilitated if all their valuable parts have the same ontological status. Aggregating the values of things of different sorts with the values of states might prove to be an overwhelming task. Also, if we reserve all value to states, we might hope to trace all such value to the value of some "basic states" that only contain "value-making" components. A similar removal of irrelevant features is, however, impossible as far as the things rather than the states are concerned: obviously, a thing cannot be stripped off a large number of its features and still exist.

But simplicity is a two-edged sword in the hands of a theorist: the theory itself is easier to handle but it may have difficulties in capturing the complexities of its subject-matter. A more compelling reason for the reduction might have to do with some influential views concerning the nature of value. According to one such group of views, there exists an essential connection between value and preference, or desire. Values are seen as accruing to objects of preferences. To be valuable is to be desirable, to be a fitting object of a preference (or, in a more subjectivist version of such a preferentialist position, it is to be an object of a preference we would have under certain ideal conditions). Now, it seems plausible to say that preferences have states as their objects and not concrete things. In those cases when we talk about preferring a thing, for example preferring an apple to an orange, it is really the having or the eating of an apple that is being preferred. ${ }^{19}$ But if objects of preferences are states and being valuable is being a fitting object for a preference, then only states can be valuable. ${ }^{20} \mathrm{~A}$ similar conclusion is reached if value is analysed in terms of pursuing or promoting. We promote states. Consequently, if value is what we should promote (or what we would promote under ideal circumstances), then - again - it is only the states that are valuable. As Ross puts it, "'good' is the name of a quality which attaches ... only to 'objectives', and not to 'substances"”.

\footnotetext{
${ }^{19}$ Instead of letting states be the objects of preference, we might interpret (some or all) preferences as attitudes de se that take one's own properties as objects (properties such as having an apple or eating an apple). Cf. Lewis (1979, esp. section 9). The difference between the "state view" and the "property view" is not really important in the present context; both views deny that preference can take concrete individuals as objects.

${ }^{20}$ But see Hansson (1998, p. 63): "It is not quite as simple as that. Some preferences are difficult to reconstruct with states of affairs as relata. As was pointed out to me by Wlodek Rabinowicz, particularly good examples of this can be found in the aesthetic realm. The [...] statement that Bartok's fourth quartet is better than his third cannot be satisfactorily expressed as a preference for the state of affairs that the fourth quartet exists (is played, is listened to) rather than the third". It is implicitly assumed in this counter-example that "better than" should be understood as "is preferable to". Consequently, the effectiveness of the counter-example crucially depends on whether value coincides with preferability. For a critical discussion of this assumption, see below.
} 
Since 'objectives' always are facts, he concludes that it is only facts that can have ultimate value (Ross, 1930, pp. $112 \mathrm{f})$.

However, even if we accept the general idea that value is what calls for an appropriate response, the response in question need not consist in just preferring or promoting. There may well be other alternatives: preference is not the only attitude to be considered, nor is promoting the only behavior that may be relevant in this context. Historically, there is the Brentanian tradition according to which values are interpreted as fitting objects of emotion: love, liking, admiration or respect. (See e.g. Brentano 1969 (1889)). Alternatively, one might relate value to thing-oriented behaviors, or perhaps better, to thing-oriented attitudes-cum-behaviors: value is what we should cherish, protect or care for. (Note, by the way, that some analyses of value in terms of appropriate emotional responses may also involve a behavioral component: there is no clear cut between feeling and behaving.) In fact, when one realises how many various types of responses could be relevant in this context, it becomes tempting to draw the conclusion that any monistic analysis of value in terms one particular type of response would be inadequate. Marcia Baron has instead proposed a pluralist treatment: a particular value may call for several different types of response, and - what is especially relevant to our concerns - different values may call for different responses (Baron 1997; for closely related pluralist views, cf. Anderson 1993, ch. 1, section 1, and Swanton 1995. $\left.{ }^{21}\right)$. As Baron puts it:

Value comes in many varieties, even if we limit ourselves [...] to non-instrumental value, and it doesn't appear that all value calls for the same response. Some are such that the best response is to exemplify or instantiate them; still others call for producing as much of them as possible; others call for honoring them by refraining from doing anything that would violate them. A mixture of these responses will often be called for, a mixture whose proper proportions may differ, depending on the value and the particular situation. (Not that there will typically be only one appropriate response or blend of responses; there will be some inappropriate ones, but often more than one appropriate response.) (Baron, 1997, p. 22)

Given such a pluralist approach to value analysis, the main motivation to reduce thing values to state values disappears. Valuable things may be objects that call for specific thing-oriented attitudes or behaviors: a wilderness untouched by human hands calls for protection, Diana's dress is an object to be cherished and preserved, and so on.

In fact, there are theorists who connect all value with non-propositional, thing- or person-oriented attitudes, such as love, respect, honouring, etc.. Elisabeth Anderson is a case in point (Anderson, 1993). Anderson therefore draws the radical conclusion that ultimate value only accrues to non-propositional entities (ibid. pp. 20ff). We need not go that far: our preferred version of the pluralist approach makes room both for propositional and non-propositional value responses.

\footnotetext{
${ }^{21}$ Baron is strongly influenced by Christine Swanton's paper. Unlike Baron, however, Swanton does not allow that different values might require different response configurations (cf. Swanton 1995, p. 49).
} 
Admittedly, if all the different attitudinal and behavioral responses to value could in their turn be reduced to preference, promotion or some combination of the two, the reduction of all value to the value of states would again become viable. But this avenue seems quite unpromising: the relevant attitudes and behavior seem to be too complex to allow such a re-construction. ${ }^{22}$

Even if non-propositional objects are admitted as bearers of intrinsic value, one might still insist that value as an end can only accrue to proposition-like entities, such as states of affairs or facts. ${ }^{23}$ After all, ends are never things. Nor are they ever persons, pace Kant. They are objectives and Ross was right in his insistence that objectives are facts rather than "substances" (Ross, ibid.). ${ }^{24}$ This means, however, that the term "value as an end" may not be quite suitable for the kind of value we have in mind when we say that a non-propositional object, such as Diana's dress or a wilderness untouched by human hands, is valued for its own sake. While a "sake" 25 may be an end, a non-propositional object can't be, even when it is valued for its own sake. Still, whereas "value as an end" is for this reason misleading, the relevant values can be said to be "end-point values", insofar as they are not simply conducive to or necessary for something else that is of value. They are "final", then, in this sense of being "ultimate".

There is a further issue lurking in the background; once we distinguish between the intrinsic and the final, the standard ad hominem regress argument for the existence of intrinsic values turns out to be based on an equivocation. The argument goes like this: Clearly, there are things we take to be valuable as means. But nothing would be valuable as means, i.e., for the sake of something else, unless there were things that are valuable for their own sakes. The sequence: $\mathrm{X}$ is valuable because it is a means for some $\mathrm{Y}$ that is valuable as a means for some $\mathrm{Z}$ that is valuable as a means for ... must, it seems, sooner or later come to an end, if we are to avoid a vicious regress. Now, however, it should be clear that this argument, if at all correct, only proves that we have to admit the existence of final values. That intrinsic values exist cannot be shown by any comparable regress argument that starts from the existence of extrinsic values. ${ }^{26}$

\footnotetext{
${ }^{22}$ See Velleman, 1999, p. 353f., for an attempt to show that such an attitude as love cannot be given a conative analysis, in terms of some states of affairs that a loving person by necessity is supposed to pursue.

${ }^{23}$ As we use the term, a "proposition-like" entity may or may not be abstract; it may or may not be spatiotemporally located and its identity criteria may be more or less stringent. The important consideration in the present context is that such entities can be objects of so-called "propositional attitudes" and thus can be referred to by means of "that"-clauses.

${ }^{24}$ But cf. Velleman (1999), pp. 355f., where it is suggested that the philosophers who interpret 'ends' as synonymous with 'aims' or 'objectives' are mistaken. The end of an action is declared by Velleman to be "that for the sake of which one acts", which clearly need not be the same as the aim of that action (if it has an aim). This rather doubtful move is used by him to defend Kant's view of persons as ends. But are we really prepared to say that the person for the sake of whom we act is the end of our action?

${ }^{25}$ The word "sake" has the same origin as the German "Sache" or the Swedish "sak". Thus, to act for someone's sake is, literally, to act for his "Sache", which may well be an end of some sort.

${ }^{26}$ Pace Korsgaard (1996 (1983), p. 259). Korsgaard, who identifies extrinsic value with Kant's notion of a conditional good, mistakenly suggests that the regress on the conditions of conditional goodness must sooner or later lead us to something that is unconditionally good. Clearly, this is a non-sequitur: it is not logically necessary for the condition of goodness to be be good itself, either conditionally or unconditionally.
} 
As we pointed out at the beginning of this paper, the intrinsic value of an object may well vary in different possible worlds, if this value supervenes on the object's contingent internal properties. In other words, one should not confuse intrinsic value with essential value, where the latter is the value that the object has by necessity, i.e., in every possible world in which it exists. This suggests, by the way, that the notion of an intrinsic value may not be as normatively interesting as many have thought. After all, what is so special with value that supervenes on the object's internal rather than relational properties, especially if the former may be just as contingent to the object as the latter ${ }^{27}$ Essential value may be more interesting, at least insofar as the necessity it involves is apriori. Then the attitudinal and behavioural norms that pertain to the essentially valuable objects will be apriori valid. However, even if such objects exist, which is by no means certain, most of what we use to be concerned about does not belong to this category and perhaps cannot even be reduced to the objects that do. On the other hand, both the ubiquity and the normative relevance of final values should be clear, at least if such values are analysed in terms of norms or desiderata concerning appropriate attitudes and behaviours. (Cf. Brülde 1998, p. 389f.)

As this difference in normative relevance suggests, the identification of final value with intrinsic value is perhaps not even prima facie reasonable. Its seeming immediate appeal may depend on our carelessness with language. The inference from "valuable for its own sake" to "valuable (as it is) in itself" is quick but invalid.

In conclusion, it seems to us that the case for irreducible final but non-intrinsic values is quite strong. Final values that accrue to things in virtue of relational features cannot be traced back to the intrinsic values of states that involve these things together with their relations. On the opposite, such states, insofar as they are valuable at all, seem to derive their value from the things involved. The endeavour to reduce thing-values to state-values is largely motivated by a mistaken belief that the appropriate responses to a valuable object at bottom always consist in preferring and/or promoting. A pluralist approach to value analysis obviates the need for reduction: the final value of a thing can be given an independent interpretation in terms of the appropriate non-propositional responses the thing in question calls for. ${ }^{28}$

${ }^{27}$ In fact, this may explain Moore's tendency to ascribe necessity to internal properties. Cf. our discussion above, at the end of the introductory section.

${ }^{28}$ As we have recently discovered, the views put forward in this paper show several similarities to the position defended in Kagan (1998). Admittedly, Kagan still continues to conflate the constitutive grounds of value with its supervenience base: He insists that, if subjectivism were true, all value would partially supervene on relational properties. Otherwise, however, his examples of final values are very similar to ours. He especially elaborates on a point that we only make in passing, in connection with Korsgaard's example of a minkcoat: In some cases, the final value of an object can supervene on its value as means. Kagan also notes that intrinsic value may well be contingent, and he draws the same conclusion as we do: It is the final values that are interesting from the normative point of view. In fact, he even takes this as a reason for a linguistic reform: He suggests we should from now on use "intrinsic value" to denote final value. We do not want to go that far. Finally, Kagan also takes up the reduction manoeuvre, i.e., the suggestion that values of things are reducible to values of states. As he notes, this move would allow one to insist that, in the end, all value for its own sake must supervene on internal properties.

Kagan, however, does not adduce any reasons to resist the reduction move. In fact, he seems to believe that such a reduction might well be successful. In this decisive respect, Kagan's position differs from ours. In our view, there 
would not be much point in the argument for final non-intrinsic values if such values after all could be reduced away to the intrinsic values of states. 


\section{References}

Anderson E., 1993. Value in Ethics and Economics. Cambridge, Mass.: Harvard University Press.

Baron Marcia W., 1997. 'Kantian Ethics', in Three Methods of Ethics, Marcia W. Baron, Philip Pettit, and Michael Slote, Oxford UK: Blackwell.

Beardsley, Monroe C., 1965. 'Intrinsic Value', Philosophy and Phenomenological Research, 26: 1- 17.

Bradley, Ben , 1998. 'Extrinsic Value', Philosophical Studies, 91: 109-26.

Brentano F., 1969 (1889). The Origin of Our Knowledge of Right and Wrong, London and Henley: Routledge \& Kegan Paul.

Broome, John, 1998. 'Normative Requirements', draft.

Bykvist, Krister, 1998. Changing Preferences: A Study in Preferentialism, Uppsala: Acta Universitatis Uppsaliensis.

Brülde, Bengt, 1998. The Human Good, Göteborg: Acta Universitatis Gothoburgensis.

Chisholm, Roderick M., 1968-9. 'The Defeat of Good and Evil.', Proceedings and Addresses of the American Philosophical Association, 42: 21-38.

Carlson, Erik, 1995. Consequentialism Reconsidered, Dordrecht: Kluwer.

Carlson, Erik, 1997. 'The Intrinsic Value of Non-Basic States of Affairs', Philosophical Studies 85: 95-107.

Dancy, Jonathan, 1993. Moral Reasons, Oxford: Blackwell.

Dancy, Jonathan, 1999. "On the Logical and Moral Adequacy of Particularism”, forthcoming in Theoria.

Feldman, Fred, 1997. 'On the Intrinsic Value of Pleasures', Ethics 107: 448-466.

Hansson, Sven Ove, 1998. Structures of Value - An Investigation of the Statics and Dynamics of Values and Norms,

Lund Philosophy Reports, Department of Philosophy, Lund University.

Harman, Gilbert H., 1967. ‘Toward a Theory of Intrinsic Value', The Journal of Philosophy 64: 792-805

Humberstone, I. L., 1996. 'Intrinsic/Extrinsic', Synthese, 108: 205-67.

Kagan, S., 1992. 'The Limits of Well-being', in The Good Life and the Human Good, eds. Ellen Frankel Paul, Fred D. Miller, Jr., and Jeffrey Paul, Cambridge University Press.

Kagan, S., 1998. 'Rethinking Intrinsic Value', The Journal of Ethics 2: 277-97.

Kant, I., 1913 (1790). Kritik der Urteilskraft, Akademieausgabe, Berlin: Verlag Georg Reimer.

Korsgaard, Christine M., 1996a. 'Two distinctions in Goodness', in Korsgaard, Creating the Kingdom of Ends, Cambridge University Press: 249-74; re-printed from The Philosophical Review XCII (1983): 169-95.

Korsgaard, Christine M., 1996b. The Sources of Normativity, Cambridge University Press.

Korsgaard, Christine M., 1997. 'The Normativity of Instrumental Reason', in Garrett Cullity and Berys Kraut (eds), Ethics and Practical Reason, Oxford University Press: 215-54.

Korsgaard, Christine M., 1998. 'Motivation, Metaphysics, and the Value of the Self: A Reply to Ginsborg, Guyer and Schneewind', Ethics 109: 49 - 66.

Lemos, Noah M., 1994. Intrinsic Value; Concept and Warrant, Cambridge University Press.

Lewis, David, 1979. 'Attitudes De Dicto and De Se’, Philosophical Review 88: 513-43. 
Moore, G. E., 1903. Principia Ethica, Cambridge: Cambridge University Press; revised edition, Cambridge: CUP 1993.

Moore, G. E., 1922. Philosophical Studies, London: Routledge and Kegan Paul.

Moore, G. E., 1965 (1912). Ethics, Oxford: Oxford University Press.

Moore, G. E., 1993. 'Preface to the second edition', in Principia Ethica, revised edition, Cambridge: Cambridge University Press.

Oldfield, Edward, 1977. 'An Approach to a Theory of Intrinsic Value', Philosophical Studies 32: 233-49.

O’Neill, John, 1992. 'The Varieties of Intrinsic Value', The Monist 75: 2: 119-137.

Pettit, Philip and Smith, Michael. 1990. 'Backgrounding Desire', The Philosophical Review 99: 565-92.

Quinn, Warren, 1974. 'Theories of Intrinsic Value', American Philosophical Quarterly 11: 123-132.

Quinn, Warren, 1977. 'Improved Foundations for a Logic of Intrinsic Value', Philosophical Studies 32:73-81

Rabinowicz, Wlodek and Österberg, Jan, 1996. 'Value Based on Preferences', Philosophy and Economics 12: 1-27

Ross W. D., 1930. The Right and the Good, Oxford University Press.

Swanton, Christine, 1995. 'Profiles of the virtues', Pacific Philosophical Quarterly 27: 335-344.

Tolhurst, William, 1983. 'On the Nature of Intrinsic Value', Philosophical Studies 43: 383-95.

Velleman, J. David, 1999, 'Love as a Moral Emotion', Ethics 109: 338-75.

von Wright, G. H., 1963. The Varieties of Goodnes, London: Routlege and Kegan Paul.

von Wright, G. H., 1972. 'The Logic of Preference Reconsidered', Theory and Decision 3: 140-169.

Zimmerman, Michael J., (1998) 'Bearers of Intrinsic Value', chapter 3 of a forthcoming book on intrinsic value. 